\title{
Reseña del libro: Reconstruyendo la educación superior a partir de la pandemia por COVID-19
}

Departamento de Formación y Actualización Académica

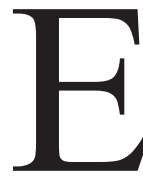

1 libro que se presenta en esta ocasión es el primer volumen de un conjunto de cinco títulos relacionados con la reformulación de la educación superior en el contexto de la emergencia sanitaria ocasionada por el virus SARS-COV-2.

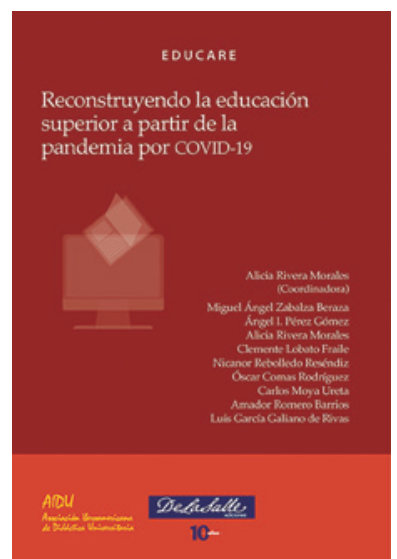

Rivera, A. (coord.) (2021).

Reconstruyendo la educación superior a partir de la pandemia por COVID-19.

Parmenia Digital. https://bit.ly/3j1Eo69

Reconstruyendo la educación superior a partir de la pandemia por COVID-19 se presenta bajo la coordinación de la doctora Alicia Rivera Morales como resultado de la colaboración con la Asociación Iberoamericana de Docencia Universitaria, representación en México. Ha sido publicado por la Editorial Parmenia de la Universidad La Salle, Ciudad de México, un órgano de extensión universitaria, cuya finalidad es la promoción del cultivo del pensamiento y la difusión del conocimiento generado por el trabajo intelectual de docentes e investigadores mexicanos y extranjeros que contribuyen al desarrollo y crecimiento del individuo, la comunidad y la sociedad.

Bajo su sello "De La Salle ediciones" de esta casa editorial universitaria, la presente obra plasma las diversas perspectivas y metodologías de nueve autores nacionales e internacionales "que abonan en la comprensión de la educación, del quehacer docente, del papel de los actores y de propuestas de intervención e innovación orientadas a la trasformación social y de las instituciones" (Rivera, 2021, p. 4), como refiere Alma Rosa Hernández Mondragón en la presentación de la obra. Se conforma por ocho capítulos, en los que se piensa la educación en torno a este tiempo de pandemia: 1. Ser profesor/a universitario en el siglo xxi: nuevos compromisos de la profesión docente; 2. Repensar el sentido de la educación en tiempos de pandemia. La formación del pensamiento práctico, el cultivo de la sabiduría; 3. La docencia y la improvisación emergente ante la falta de planeación en tiempos de pandemia; 4. Fomentando la práctica reflexiva a través de la supervisión de la práctica profesional; 5. Educación intercultural: reflexiones sobre dos décadas de interculturalismo en México; 6. El papel de los sentidos en la educación a distancia; 7. A la sombra del árbol del siglo XXI. Crisis, docencia y transformación universitarias; y finalmente 8 . Pedagogía y arquitectura en el siglo Xx, un diálogo imbricado.

En el primer capítulo el autor hace un análisis sobre cómo se desarrolla el proceso de enseñanza en las universidades españolas ante esta crisis mundial sanitaria, pero también reflexiona acerca del lado bueno de esta situación: innovar en la manera de dar clases, la búsqueda de nuevas didácticas y no repetir las mismas ideas y esquemas del trabajo educativo. Finalmente, sugiere algunas condiciones en las que los docentes deberán ejercer su profesión, acorde con los cambios del entorno que afectan el modo de ejercer la educación.

En el segundo capítulo, el autor expone diez retos relacionados con: 1) el aprender a vivir en la incertidumbre y manejar la fragilidad y el cambio permanente; 2) cultivar la sabiduría; 3 ) promover el cuidado y la cooperación; 4) priorizar lo esencial, relevancia y calidad del saber; 5) fomentar la consciencia ecológica; 6) bus- 
car la coherencia educativa en el decir, pensar y hacer; 7) comprender, aprovechar y disfrutar educativamente los potentes escenarios virtuales; 8) cambiar la manera de mirar el aprendizaje (esto es, transformando la información recibida en conocimiento propio, autónomo, activo y útil para comprender y actuar); 9) establecer una nueva cultura pedagógica, desarrollando en cada individuo sus cualidades y capacidades o competencias, junto con sus conocimientos, habilidades, emociones, actitudes y valores, a fin de reconstruirlos mediante la reflexión en y sobre la acción; y finalmente, 10) el docente requiere cualidades más complejas y distintas a las que ya se conocían tradicionalmente, con la finalidad de contribuir a que cada estudiante cree su propio proyecto personal, académico y profesional, volviéndose un ciudadano culto, solidario y autónomo (Pérez en Rivera, A., 2021, p. 42).

La docencia y la improvisación emergentes se desarrollan en el tercer capítulo del libro, donde la autora hace referencia a la complejidad de la condición humana ante una situación imprevisible, en tres apartados: 1) el cambio que rompió con la "normalidad", cuando la educación pasó de las aulas físicas a las virtuales; 2) la complejidad de la docencia en la "nueva normalidad"; y 3 ) en el futuro inmediato: fragmentos de una utopía frente a una pandemia que, citando a Edgar Morín, se invita a repensar los procesos de enseñanza y aprendizaje.

En el cuarto capítulo, se exponen las claves fundamentales de la formación de profesionales a través de la reflexión, todo desde un modelo de supervisión integrativa como metodología de desarrollo profesional docente. Esta metodología "pretende integrar tanto las dimensiones cognitivas como las emocionales y comportamentales del ser humano" (Lobato en Rivera, A., 2021, p. 63), orientada a la formación de profesionales reflexivos críticos, "comprometidos en una docencia de calidad para la mejora de un aprendizaje universitario y una transformación en el ámbito socioeducativo" (Lobato en Rivera, A., 2021, p. 68).

La interculturalidad como discurso político-pedagógico se hace presente en el quinto capítulo del libro, donde el autor expone "las diferencias entre interculturalismo funcional (estado liberal) y el interculturalismo crítico decolonial (organizaciones indígenas)" (Rivera, 2021, p. 8). Partiendo de esta discusión, se reflexiona sobre la problemática de la educación intercultural en México de las últimas dos décadas, y cómo ésta es importante para desarrollar la interacción entre culturas diferentes, integradas a través de la instauración de un sistema de derechos fundamentales que contribuyan a que cada individuo puede ser educado "de acuerdo con su propia cultura e idioma, y orientada a proteger y fortalecer las lenguas indígenas" (Rebolledo en Rivera, A., 2021, p. 75).

En el sexto capítulo se reflexiona acerca del impacto que ha tenido la pandemia en los procesos de enseñanza y aprendizaje donde los sentidos son fundamentales para lograr el aprendizaje. Sin embargo, hoy en día sólo dos de estos sentidos se han vuelto principales y tres asociados en la educación a distancia. “¿Cómo esto cambiará el entorno educativo y social de los estudiantes y del profesorado?" (Comas y Rivera en Rivera, A., 2021, p. 85). A partir de esta cuestión, los autores sugieren que el docente disponga de recursos personales y materiales que estimulen de alguna forma los sentidos para hacerse entender, y así los estudiantes adquieran un aprendizaje significativo en sus clases virtuales.

En el séptimo capítulo se hace un análisis sobre el impacto que la pandemia ha dejado en el desenvolvimiento de las prácticas y de la cultura del trabajo universitario, así como una reflexión sobre la docencia universitaria en el horizonte del siglo xxI. El texto se divide en tres partes: 1) Pandemia y docencia universitaria; 2) Crisis y desafíos de la docencia universitaria. En la perspectiva del siglo XxI; y 3) Proyecto de universidad y formación docente. Preguntas generadoras donde el autor plantea una serie de cuestionamientos que conllevan a "relevar dimensiones no evidentes de la crisis ético-formativa que invade las prácticas docentes y su precarización institucional, tomando como referencia algunos resultados de investigaciones aplicadas al caso de la realidad universitaria chilena, y por extensión, a la situación declarada en instituciones latinoamericanas" (Moya en Rivera, A., 2021, p. 89).

Por último, en el octavo capítulo se aborda el tema sobre si en estos momentos de pandemia los espacios escolares deben ser reconsiderados, arquitectónicamente hablando. Se trata de una invitación a replantear el diálogo entre pedagogos, docentes, alumnos, arquitectos y diseñadores a fin de proyectar y construir nuevas espacialidades escolares "acordes con las necesidades actuales de aprender con el menor riesgo de contagio" (Romero y Galiano en Rivera, A., 2021, p. 118), tomando en cuenta algunas propuestas arquitectónicas que se dieron durante el primer cuarto del siglo xx en México.

\section{Fuentes de consulta}

Rivera, A. (Coord.). (2021). Reconstruyendo la educación superior a partir de la pandemia por COVID-19. Editorial Parmenia. Recuperado de https:// bit.ly/3j1Eo69 